\title{
The incidence of sensory integration problems in a distinct sample of individuals with disorders characterised by symptoms of psychosis
}

\author{
Tharina Annandale, M OT (UFS)
}

Annamarie van Jaarsveld, M OT (UFS)

Rita van Heerden, M OT (UFS), PhD (HPE) (UFS)

Department of Occupational Therapy, Faculty of Health Sciences, University of the Free State, Bloemfontein, South Africa

Riette Nel, MMedSc (UFS)

Department of Biostatistics, Faculty of Health Sciences, University of the Free State, Bloemfontein, South Africa

Background: Individuals with psychosis present with functional problems that impact negatively on their occupational performance. The framework of sensory integration provides for the assessment and treatment of occupational performance problems related to functions supported by the sensory systems.

Methods: The incidence of sensory integration problems in individuals with disorders characterised by symptoms of psychosis was investigated by using a descriptive study design. Forty-nine (49) adult individuals with symptoms of psychosis admitted to acute wards of a psychiatric institution in South Africa participated in the study. The sensory integration functions of the individuals were established using the Schroeder, Block and Campbell Adult Psychiatric Sensory Integration Evaluation (SBC).

Results: The results indicated that the individuals with disorders characterised by symptoms of psychosis experienced sensory integration problems.

Conclusion: The incidence of sensory integration problems found in this study warrants further research with regard to the effect of sensory integration intervention on the mental healthcare user with disorders characterised by symptoms of psychosis.

Key words: Psychosis, occupational therapy, sensory integration problems

\section{INTRODUCTION}

Individuals with psychosis present with problems that impair functionality and occupational performance'. According to the Occupational Therapy Practice Framework ${ }^{2}$, occupational performance can be defined as the method or way in which people engage in meaningful activities or occupations such as self-care, recreation and work. Occupational therapists are concerned with the occupational performance of individuals that includes occupations, client factors, performance skills, performance patterns, and the context and environment in which an individual functions ${ }^{2}$. If any of these are challenged, it is within the scope of practice of the occupational therapist to address occupational performance through the use of appropriate intervention. Thus, the sensory profile of an individual has to be identified as the personal factor that should be addressed in order to enhance occupational performance.

This study aimed to investigate the incidence of sensory integration problems in the individual with psychosis and how it affects the individual's occupational performance.

Components of the client factors (beliefs, spirituality, body functions and body structures) ${ }^{2}$ have their roots in the sensory systems. The vestibular system, for instance, controls a person's balance, equilibrium and postural patterns. When the vestibular system is unable to integrate and process vestibular information accurately, the individual's praxis ability will be affected, thus influencing the general motor functioning.

Although older literature ${ }^{3-6}$ on sensory integration in individuals with chronic schizophrenia supports the existence of sensory integration problems among such persons, no research has been published to date on individuals with disorders characterised by symptoms of psychosis in South Africa. As part of a more compre- hensive research project ${ }^{7}$ that established the short-term effect of sensory integration intervention on the individual with psychosis, a group of 49 individuals with psychosis were assessed. In the more comprehensive study, 99 individuals with psychosis were included. Forty-nine (49) of these individuals (the experimental group) were assessed by means of a sensory integration assessment tool and the remaining 50 participants were not formally assessed. The experimental group forms the focus of this article. Although a relatively small sample was investigated, the results of this component of the study will contribute to the body of knowledge regarding the incidence of sensory integration problems among individuals with psychosis. If occupational therapists trained in the use of sensory integration are aware of these problems, a treatment regime can be established accordingly.

\section{LITERATURE REVIEW}

For the purpose of this study, the authors accentuated the literature ${ }^{3-6,8-10}$ on psychosis and the existence of sensory integration problems in the individual with a mental health condition. The Synopsis of Psychiatry ${ }^{8}$ and the Diagnostic and Statistical Manual of Mental Disorders ${ }^{10}$ were the main literature sources on psychosis, schizophrenia and bipolar disorder in the manic phase.

Psychotic disorders are characterised by hallucinations, delusions, poor reality orientation, disorganised speech and inappropriate behaviour ${ }^{8}$. Uys and Middleton ${ }^{9}$ refer to psychosis as the inability to recognise or identify reality, to think and to communicate. The individual with psychosis has inappropriate behaviour and can react emotionally (abnormal crying, aggressive and labile behaviour) towards other people's behaviour. This behaviour is caused by an inability of the brain to control neurotransmitters and is the main 
cause of mental health conditions, such as schizophrenia and bipolar disorder. In the fifth edition of the Diagnostic and Statistical Manual of Mental Disorders-5 (DSM-5) $)^{10}$, schizophrenia is described as a psychotic disorder where the clinical picture can include one or more of the following symptoms: delusions, hallucinations, disorganised speech, inappropriate or catatonic behaviour, blunted affect, decreased speech and motivation. Uys and Middleton ${ }^{9}$ explain that schizophrenia can also limit communication and awareness of reality.

Neurotransmitters are involved in complex interactional relations with other body functions, and therefore abnormal sensory integration functions and schizophrenia can be caused by changes in serotonin, norepinephrine, dopamine and other amino acids ${ }^{8}$. Other changes that can possibly cause sensory integration dysfunctions and schizophrenia are neuroanatomical changes in the limbic system, basal ganglia, cerebellum, prefrontal cortex and thalamus ${ }^{8}$. Thus, a critical review of the interactional relations of the neurotransmitters and anatomical changes of the individual with schizophrenia was done in order to form a theoretical foundation for the possible presence of sensory integration problems in the individual with psychosis.

According to Sadock and Sadock ${ }^{8}$, one of the main characteristics of bipolar disorder is a labile mood as well as aggressive behaviour, decreased sleep and increased activity levels. Neurological changes in bipolar disorder can possibly lead to sensory integration dysfunctions. These changes include changes in the serotonin, dopamine and lithium, as well as changes in the neuro-anatomy of the prefrontal cortex, thalamus and limbic system ${ }^{8}$. Thus, in the individual with bipolar disorder, the ability to process sensory information and plan goal-directed behaviour can be affected. If an individual with schizophrenia or bipolar disorder cannot process sensory information and act on it accordingly, their ability to function independently and perform activities of daily living is affected.

Therefore, we can conclude that the individual with schizophrenia or bipolar disorder can has decreased occupational performance; for example, in work, recreation, interpersonal relations and personal care. According to the literature ${ }^{3}$, sensory integration has a profound role to play in the occupational performance of each individual. In order to work, play and have meaningful interpersonal relationships with others, the individual's client factors ${ }^{2}$ should function to such a degree that the person can focus, obtain and maintain concentration, follow instructions and plan activities for successful execution. It is also of importance to have appropriate emotional responses and emotional regulation in a meaningful relationship and within a work environment.

The ability to process and integrate sensory information will influence client factors and will therefore have a direct impact on occupational performance.

In this article, the authors will discuss the incidence of sensory integration problems of a distinct sample of individuals with psychosis. In order to investigate the incidence of these problems, the authors reviewed related published literature ${ }^{3-6}$ on the topic and found that the information on the incidence of the sensory integration problems of the mental healthcare user was very limited. The only articles that could be found on this specific topic were published in 19745, $1977^{6}$ and $1978^{4}$. All these studies were conducted on individuals with chronic schizophrenia. The lack of current literature on this topic warrants the aim of this study - to explore the incidence of sensory integration problems of the individual with psychosis.

Although the available literature was older, it supported the possible existence of sensory integration problems in the individual with psychosis. King ${ }^{5}$ referred to the fact that poor postural control, shuffling gait and other movement disorders of individuals with schizophrenia can be due to sensory integration dysfunction. The abovementioned problems can contribute to praxis dysfunctions ${ }^{7}$ and has also been confirmed by Alers'.

In the 1970s, King ${ }^{5}$ already confirmed the presence of poor processing within the proprioceptive system of individuals with schizophrenia. The results of this research were confirmed by Levine et al. ${ }^{6}$, who found that individuals with schizophrenia have problems with motor planning, body image and other visual perceptual problems. Bailey ${ }^{4}$ found that the individual with schizophrenia has illogical and delayed speech and instability with walking. It can be concluded that the individual with psychosis can possibly have sensory integration problems.

Thus, this study aimed to explore the incidence of sensory integration problems among individuals with psychosis and a specific sample was used to address this aim.

\section{METHODOLOGY}

\section{Study design}

A descriptive study design was used to describe the incidence of sensory integration problems of individuals with symptoms of psychosis".

\section{Population and sampling}

A randomised, controlled, single blind clinical trial was performed and sampling was done by convenience sampling'". The sample included individuals with psychosis, admitted to one mental health institution in South Africa. A sample size of 49 participants was drawn from the population.

The individuals included in this study were:

$*$ between 18 and 59 years of age;

$*$ admitted to the acute wards of the specific institution;

* diagnosed with psychosis by a psychiatrist; if the individual became a-psychotic, he/she continued to participate in the study;

* diagnosed by a psychiatrist with an Axis-I diagnosis ${ }^{12}$ of schizophrenia or bipolar disorder in the manic phase (at the time of the data collection the DSM IV was still in use);

* diagnosed with a first episode of psychosis or an acute exacerbation of their chronic psychiatric condition; and

* compliant with treatment prescribed by a psychiatrist.

\section{Exclusion criteria}

Individuals with epilepsy, mental retardation, deafness, blindness, or a physical disability were excluded from the study due to the fact that the additional pathologies added variables that could not be controlled.

\section{Measurement tool}

The data were collected with two measurement tools. Firstly, a daily clinical record of the participants' symptoms which were collected from the clinical records. The clinical picture and medication were noted on a daily basis according to the medical files and notes of the multi-professional team, and data were extracted from the records in the files. This was specifically done by the occupational therapist working in the wards at that time, in order to control variables and the influence of medication on the functionality of the individuals.

The second measurement instrument used was the Schroeder, Block and Campbell Adult Psychiatric Sensory Integration Evaluation $(\mathrm{SBC})^{13}$.

The SBC is a measuring instrument that was designed by Carolyn van Schroeder, Marjorie Papke Block, Elizabeth Campbelle Trottier and Mary Savage Stowell, and the third edition was published in 1993. It was developed to meet the need for a sensory integration assessment tool in adult psychiatry. For the purpose of this study, the instrument was used to establish the sensory integration function and problems of the individual with psychosis. The SBC was the only instrument identified that could support the aim of this study. The SBC makes use of demonstration and therefore language barriers could be controlled. Two occupational therapists trained in sensory integration and the administering of the SBC assessed the participants and rotated on a three-monthly basis. It was previously used in research ${ }^{14-15}$ on adults with mental health problems. Bruce and Borg ${ }^{14}$ referred to the fact that they had used this measuring instrument for twenty years in the adult mental health field, and that 
it had been a reliable instrument that could assess the incidence of sensory integration problems.

Although the authors could not find any literature on the psychometric information of the SBC, previous studies have been conducted and proved that the SBC is a valid and reliable measurement tool. In a study ${ }^{15}$ where 113 individuals with a psychiatric diagnosis and I 3 typical individuals were assessed with the SBC, the individuals differed significantly in their scores for abnormal movements and physical assessment. The typical individuals had typical performance on the SBC and the individuals with psychiatric diagnosis had atypical performance.

The SBC assesses the following aspects of client factors ${ }^{13}$ : sensory and motor responses, reflex integration, fine- and gross motor skills, abnormal movements, body image and soft neurological signs.

The score sheet of the SBC was compiled by the principal researcher. It was used to summarise the raw scores and included the following: dominance, posture, neck rotation, gait, bilateral coordination, midline crossing, stability, Sharpened Romberg, tonic labyrinthine reflex, protective extension, seated equilibrium, body image, diadochokinesia, finger-thumb opposition and visual pursuits.

The terminology is defined as follows:

$*$ Neck rotation is dependent on postural control and plays an important role in the ability of the individual to differentiate between neck and trunk movements ${ }^{16}$.

* Gait: Well established gait is supported by postural control, balance, equilibrium and bilateral coordination ${ }^{16}$.

$*$ Bilateral coordination is the ability to use a leading limb and an assisting limb together. This ability is influenced by postural control and the ability to keep the body in a specific position ${ }^{16}$.

$*$ Midline crossing is an important part of bilateral coordination and often occurs in conjunction with weight shifting, stability and trunk rotation ${ }^{16}$.

* Stability of the upper extremities is dependent on postural control and influences bilateral coordination and midline crossing ${ }^{16}$.

* Sharpened Romberg: This test is used to establish whether the individual can hold a position without losing their balance. The test is performed with eyes open and eyes closed in order to establish whether there is a marked difference between the two items. In the case of a marked difference, it can be indicative of a vestibular-proprioceptive processing dysfunction ${ }^{16}$.

$*$ Tonic labyrinthine reflex is present at $0-3$ years of age, where after it should be integrated. If the tonic labyrinthine reflex is not well integrated after the age of 3 years, it can influence the normal development of muscle tone and thus influence the development of postural control, balance, equilibrium and bilateral coordination ${ }^{17}$.

* Protective extension, equilibrium and body image form the basis of active movement and prevent an individual from falling, while enhancing postural control ${ }^{16}$. Seated equilibrium and protective extension entail weight shifting and require postural control and normal muscle tone ${ }^{16}$.

* Diadochokinesia is the alternating movement of a hand or hands indicating the ability to perform fast rotational movements of the forearm ${ }^{18}$, which in turn reflects refined use of the forearm.

* Finger-thumb movements: Finger-thumb opposition requires the individual to alternate movement of the thumb to each of the other fingers individually and in a sequential manner ${ }^{18}$.

\section{Methods and procedures}

Ethical procedures were followed and permission was given by the head of the institution on behalf of the individuals with psychosis, prior to conducting the pilot study.

The demographic information was collected by the occupational therapist in the ward. The level of psychosis, clinical picture and medication of each participant were noted on a daily basis according to the medical files and multidisciplinary notes. The day and time of assessments were in accordance with the standard program of the ward.
The SBC assessments were conducted on an individual, oneto-one basis and findings were noted on a score sheet. Instructions were demonstrated to participants that did not understand English.

\section{Data analysis}

The Department of Biostatistics at the University of the Free State assisted with the data analysis of this study. The raw data were presented by means of a summarised score sheet of the measurement instrument. The initial measurements were summarised by means of descriptive statistics, namely frequencies and percentages of categorical data, medians and percentiles. Due to the fact that $95 \%$ confidence intervals were used to project the results directly onto the data scale, no $\mathrm{p}$-values were needed in the study ${ }^{19}$. The data analysis for this study was done by means of the SAS software (SAS Institute Inc., Cary, NC, USA).

\section{Ethics}

The Ethics Committee of the Faculty of Health Sciences of the University of the Free State approved the study (ETOVS number 30/I I). The registration number of the study at the National Health Research Ethics Committee (NHREC) is DOH/27/06 II/3545. Permission for participation of individuals who adhered to the inclusion criteria was provided by the institution during the participants' psychotic phase of their mental illness. If the individuals reached the a-psychotic phase of their mental illness within the time that they participated in the study, an oral and written explanation of the research and implication thereof were given to the participants and they had the right to participate or withdraw from the study at any time. Three of the individuals were psychotic when first included in the study, but became a-psychotic during the study. The participants' information remained confidential at all times and their right to privacy and humanity was respected throughout. It was explained to participants that the study would have no financial benefits or hold any cost for the research individuals. The right to intervention and pharmacological treatment was respected throughout and the individuals who were assessed received intervention accordingly.

\section{RESULTS}

The incidence of the sensory integration problems of the individual with psychosis are discussed within the context of a sample of 49 adults who had been admitted to one mental health institution in South Africa. The results can be used to establish whether the participants had sensory integration problems and as foundation for future intervention.

The demographic information will be discussed to clarify the variables and factors that could have influenced the incidence of sensory integration problems within the sample.

\section{Demographic information}

All cultures and both genders were included in the study. The median age of the individuals was 32 years (range 20-57 years) and they were mostly male $(65.3 \%)$. All the individuals used medication that inhibited behaviour and $20.4 \%$ ) of the individuals used medication that improved awareness.

The results on the participants' HIV status, cannabis abuse and pathology are summarised in Table I on page 33. The HIV status of the participants were mostly $(79.6 \%)$ unknown, while 22 (44.9\%) participants tested positive for cannabis. Approximately two thirds (63.3\%) of the participants were diagnosed with schizophrenia, while $36.7 \%$ were diagnosed with bipolar disorder in the manic phase.

The type of medication prescribed to inhibit behaviour, such as agitation and irritability, was given to $100 \%$ of the participants during the test stages of the study.

\section{Results of the SBC}

The results of the SBC regarding the more pronounced sensory integration problems that were present within this sample of in- 
Table I: Participants' gender, HIV status, cannabis abuse and pathology

\begin{tabular}{|l|c|c|}
\hline & \multicolumn{2}{|c|}{ (n=49) } \\
\hline Gender & 32 & 65.3 \\
\hline Male & 17 & 34.7 \\
\hline Female & 5 & 10.2 \\
\hline HIV status & 5 & 10.2 \\
\hline Positive & 39 & 79.6 \\
\hline Negative & \multicolumn{2}{|}{} \\
\hline Unknown & 22 & 44.9 \\
\hline Cannabis abuse & 27 & 55.1 \\
\hline Tested positive & 31 & 63.3 \\
\hline Tested negative & 18 & 36.7 \\
\hline Pathology &
\end{tabular}

dividuals with disorders characterised by symptoms of psychosis, are presented below. The following key, according to the SBC, was used to rate the individuals:

I. normal/well integrated sensory integration processing.

2. slight difficulty/challenges in sensory integration processing.

3. moderate difficulty/challenges in sensory integration processing.

4. severe difficulty/challenges in sensory integration processing.

The SBC allows that aspects of the assessments can be omitted when it is too difficult for the individual to perform and therefore some of the aspects have missing frequencies. However, it did not have a pronounced influence on the final percentiles.

\section{Vestibular-proprioceptive system}

Dominance frequency (percentage)

According to the results in Table II, most of the individuals' dominance was integrated and can therefore be recognised as normal.

Table II: Dominance

\begin{tabular}{|l|c|c|c|c|}
\hline \multirow{2}{*}{ Dominance } & \multirow{2}{*}{ Normal } & \multicolumn{3}{|c|}{ Severity of problem } \\
\cline { 3 - 5 } & & Slight & Moderate & Severe \\
\hline Eye $(n=49)$ & $42(85.7 \%)$ & $7(14.3 \%)$ & 0 & 0 \\
\hline Hand $(n=49)$ & $38(77.6 \%)$ & II (22.5\%) & 0 & 0 \\
\hline Foot $(n=49)$ & $35(71.4 \%)$ & I3(26.5\%) & 0 & $\begin{array}{c}\text { I } \\
\end{array}$ \\
& & & & $(2.0 \%)$ \\
\hline
\end{tabular}

Posture, neck rotation and gait frequency (percentage) (Table III)

Slightly more than a third (34.7\%) of the individuals had well integrated posture, and less than half $(49.0 \%)$ had either a moderate or severe challenge with posture. Only $10.4 \%$ of the individuals had well integrated neck rotation and more than half $(52.1 \%)$ experienced difficulties.

Approximately one third (35.4\%) of the individuals had normal gait, while $29.2 \%$ of the individuals obtained moderate or severe scores indicating difficulties with gait.

Bilateral coordination - upper extremities, midline crossing, stability - upper extremities frequency (percentage) (Table IV)

Only $6.3 \%$ of the individuals had normal bilateral coordination of the upper extremities, and $73 \%$ experienced moderate to severe
Table III: Posture, neck rotation and gait

\begin{tabular}{|c|c|c|c|c|c|}
\hline \multirow{2}{*}{ Aspects } & \multirow{2}{*}{ Normal } & \multicolumn{3}{|c|}{ Severity of problem } & \multirow{2}{*}{$\begin{array}{l}95 \% \\
\text { Cl* }\end{array}$} \\
\hline & & Slight & Moderate & Severe & \\
\hline & $\begin{array}{c}17 \\
34.7 \%)\end{array}$ & $\begin{array}{c}8 \\
(16.3 \%)\end{array}$ & $\begin{array}{c}12 \\
(24.5 \%)\end{array}$ & $\begin{array}{c}12 \\
(24.5 \%)\end{array}$ & \\
\hline $\begin{array}{l}\text { Neck } \\
\text { rotation } \\
(n=48)\end{array}$ & $\begin{array}{c}5 \\
(10.4 \%)\end{array}$ & $\begin{array}{c}18 \\
(37.5 \%)\end{array}$ & $\begin{array}{c}18 \\
(37.5 \%)\end{array}$ & $\begin{array}{c}7 \\
(14.6 \%)\end{array}$ & \\
\hline $\begin{array}{l}\text { Gait } \\
(n=48)\end{array}$ & $\begin{array}{c}17 \\
(35.4 \%)\end{array}$ & $\begin{array}{c}17 \\
(35.4 \%)\end{array}$ & & $\begin{array}{c}12 \\
(25.0 \%)\end{array}$ & $\begin{array}{l}\text { [14.9\%; } \\
38.8 \%]\end{array}$ \\
\hline
\end{tabular}

* $95 \% \mathrm{Cl}$ for the incidence of severe difficulty

Table IV: Bilateral coordination, midline crossing and stability of upper extremities

\begin{tabular}{|c|c|c|c|c|c|}
\hline \multirow{2}{*}{ Aspects } & \multirow{2}{*}{ Normal } & \multicolumn{3}{|c|}{ Severity of problem } & \multirow{2}{*}{$\begin{array}{l}95 \% \\
\text { Cl* }\end{array}$} \\
\hline & & Slight & Moderate & Severe & \\
\hline $\begin{array}{l}\text { Bilateral } \\
\text { coordination } \\
\text { - upper } \\
\text { extremities } \\
(n=48)\end{array}$ & $\begin{array}{c}3 \\
(6.3 \%)\end{array}$ & $\begin{array}{c}10 \\
(20.8 \%)\end{array}$ & $\begin{array}{c}14 \\
(29.2 \%)\end{array}$ & $\begin{array}{c}21 \\
(43.8 \%)\end{array}$ & $\begin{array}{c}\text { [30.7\%; } \\
57.7 \%]\end{array}$ \\
\hline $\begin{array}{l}\text { Midline } \\
\text { crossing } \\
(n=49)\end{array}$ & $\begin{array}{c}19 \\
(38.8 \%)\end{array}$ & $\begin{array}{c}9 \\
(18.4 \%)\end{array}$ & $3(6.1 \%)$ & $\begin{array}{c}18 \\
(36.7 \%)\end{array}$ & $\begin{array}{l}\text { [24.7\%; } \\
50.7 \%]\end{array}$ \\
\hline $\begin{array}{l}\text { Stability } \\
\text { - upper } \\
\text { extremities } \\
(n=49)\end{array}$ & $\begin{array}{c}8 \\
(16.3 \%)\end{array}$ & $\begin{array}{c}\text { II } \\
(22.5 \%)\end{array}$ & $\begin{array}{c}19 \\
(38.8 \%)\end{array}$ & $\begin{array}{c}\text { II } \\
(22.5 \%)\end{array}$ & $\begin{array}{l}\text { [13.0\%; } \\
35.9 \%]\end{array}$ \\
\hline
\end{tabular}

*95 $\mathrm{Cl} \%$ for the incidence of severe difficulty

Table V: Sharpened Romberg

\begin{tabular}{|c|c|c|c|c|c|}
\hline \multirow{2}{*}{$\begin{array}{l}\text { Sharpened } \\
\text { Romberg }\end{array}$} & \multirow[t]{2}{*}{ Normal } & \multicolumn{3}{|c|}{ Severity of problem } & \multirow{2}{*}{$\begin{array}{l}95 \% \\
\text { Cl* }\end{array}$} \\
\hline & & Slight & Moderate & Severe & \\
\hline $\begin{array}{l}\text { Eyes open } \\
(n=47)\end{array}$ & $\begin{array}{c}19 \\
(40.4 \%)\end{array}$ & $\begin{array}{c}7 \\
(14.9 \%)\end{array}$ & & $\begin{array}{c}18 \\
(38.3 \%)\end{array}$ & $\begin{array}{l}{[25.8 \% \text {; }} \\
52.6 \%]\end{array}$ \\
\hline $\begin{array}{l}\text { Eyes closed } \\
(n=47)\end{array}$ & $\begin{array}{c}4 \\
(8.5 \%)\end{array}$ & $\begin{array}{c}6 \\
(12.8 \%)\end{array}$ & & $\begin{array}{c}30 \\
(63.8 \%)\end{array}$ & $\begin{array}{l}{[49.5 \% \text {; }} \\
76.0 \%]\end{array}$ \\
\hline
\end{tabular}

* $95 \% \mathrm{Cl}$ for the incidence of severe difficulty

challenges with this aspect.

Approximately $40 \%$ of the individuals had well integrated midline crossing, whilst $42.8 \%$ experienced moderate to severe challenges with midline crossing.

More than $60 \%$ of the individuals experienced moderate to severe challenges with stability of the upper extremities.

Sharpened Romberg: eyes open and eye closed frequency (percentage)

As shown in Table V, $40.4 \%$ of the individuals did not experience any challenges with the sharpened Romberg (eyes open), but $44.7 \%$ of the individuals experienced moderate to severe challenges.

Most (78.7\%) of the individuals experienced moderate to severe challenges with the Sharpened Romberg test (eyes closed). The results demonstrate that the individual with psychosis that participated in this study experienced problems with weight shifting and protective extension and that some of the individuals compensated with vision.

Tonic labyrinthine reflex frequency (percentage)

Only $6.4 \%$ of the individuals' tonic labyrinthine reflexes were well integrated, while $80.8 \%$ experienced moderate to severe challenges 
(Table VI). The $95 \% \mathrm{Cl}$ for the incidence of moderate difficulties was [22.2\%; 48.3\%].

Protective extension, seated equilibrium, body image frequency (percentage)

The results depicted in Table $\mathrm{VI}$ indicate that $35.5 \%$ of the individuals experienced moderate to severe challenges with protective extension. Approximately $45 \%$ of the individuals displayed moderate challenges with seated equilibrium, with a $95 \% \mathrm{Cl}$ of [31.4\%; 58.8\%]). Moderate to severe body image difficulties were experienced by $47.9 \%$ of the individuals, , while only $16.7 \%$ experienced no problems.

Table VI: Tonic labyrinthine reflex, protective extension, seated equilibrium and body image

\begin{tabular}{|c|c|c|c|c|c|}
\hline \multirow[t]{2}{*}{ Aspect } & \multirow[t]{2}{*}{ Normal } & \multicolumn{3}{|c|}{ Level of difficulty } & \multirow{2}{*}{$\begin{array}{c}95 \% \\
\text { Cl* }\end{array}$} \\
\hline & & Slight & Moderate & Severe & \\
\hline $\begin{array}{l}\text { Tonic } \\
\text { labyrinthine } \\
\text { reflex } \\
(\mathrm{n}=47)\end{array}$ & $\begin{array}{c}3 \\
(6.4 \%)\end{array}$ & $\begin{array}{c}6 \\
(12.8 \%)\end{array}$ & $\begin{array}{c}16 \\
(34.0 \%)\end{array}$ & $\begin{array}{c}22 \\
(46.8 \%)\end{array}$ & $\begin{array}{l}\text { [33.3\%; } \\
60.8 \%]\end{array}$ \\
\hline $\begin{array}{l}\text { Protective } \\
\text { extension } \\
(n=48)\end{array}$ & $\begin{array}{c}8 \\
(16.7 \%)\end{array}$ & $\begin{array}{c}23 \\
(47.9 \%)\end{array}$ & $\begin{array}{c}14 \\
(29.2 \%)\end{array}$ & $\begin{array}{c}3 \\
(6.3 \%)\end{array}$ & $\begin{array}{l}{[2.1 \% ;} \\
16.8 \%]\end{array}$ \\
\hline $\begin{array}{l}\text { Seated } \\
\text { equilibrium } \\
(n=47)\end{array}$ & $\begin{array}{c}18 \\
(38.3 \%)\end{array}$ & $\begin{array}{c}3 \\
(6.4 \%)\end{array}$ & $\begin{array}{c}21 \\
(44.7 \%)\end{array}$ & $\begin{array}{c}5 \\
(10.6 \%)\end{array}$ & $\begin{array}{l}\text { [31.4\%; } \\
58.8 \%]\end{array}$ \\
\hline $\begin{array}{l}\text { Body } \\
\text { image } \\
(n=48)\end{array}$ & $\begin{array}{c}8 \\
(16.7 \%)\end{array}$ & $\begin{array}{c}16 \\
(33.3 \%)\end{array}$ & $4(8.3 \%)$ & $\begin{array}{c}19 \\
(39.6 \%)\end{array}$ & $\begin{array}{l}\text { [27.0\%; } \\
53.7 \%]\end{array}$ \\
\hline
\end{tabular}

$* 95 \% \mathrm{Cl}$ for the incidence of severe difficulty

\section{Somatosensory system (tactile and proprioceptive)}

\section{Diadochokinesia, finger-thumb opposition frequency (percentage)}

Only $10.2 \%$ of the individuals' ability to perform rotational forearm movements were well integrated, while $5 \mathrm{I} \%$ of the individuals experienced moderate to severe difficulties (Table VII). The incidence for moderate difficulties with diadochokinesia were $36.7 \%$, with a $95 \% \mathrm{Cl}$ of $[24.7 \% ; 50.7 \%]$.

Only $10.2 \%$ of the individuals could perform finger-thumb movements in a coordinated manner, while $77.6 \%$ of the individuals experienced moderate to severe difficulties.

Table VII: Diadochokinesia and finger-thumb opposition

\begin{tabular}{|c|c|c|c|c|c|}
\hline \multirow[t]{2}{*}{ Aspect } & \multirow[t]{2}{*}{ Normal } & \multicolumn{3}{|c|}{ Severity of problem } & \multirow[t]{2}{*}{$95 \% \mathrm{Cl} *$} \\
\hline & & Slight & Moderate & Severe & \\
\hline $\begin{array}{l}\text { Diadocho- } \\
\text { kinesia } \\
(n=49)\end{array}$ & $\begin{array}{c}5 \\
(10.2 \%)\end{array}$ & $\begin{array}{c}19 \\
(38.8 \%)\end{array}$ & $\begin{array}{c}18 \\
(36.7 \%)\end{array}$ & $\begin{array}{c}7 \\
(14.3 \%)\end{array}$ & $\begin{array}{l}\text { [7.1\%; } \\
26.7 \%]\end{array}$ \\
\hline $\begin{array}{l}\text { Finger- } \\
\text { thumb } \\
\text { opposition } \\
(n=49)\end{array}$ & $\begin{array}{c}5 \\
(10.2 \%)\end{array}$ & $\begin{array}{c}6 \\
(12.2 \%)\end{array}$ & $9(18.4 \%)$ & $\begin{array}{c}29 \\
(59.2 \%)\end{array}$ & $\begin{array}{l}\text { [45.2\%; } \\
71.8 \%]\end{array}$ \\
\hline
\end{tabular}

$* 95 \% \mathrm{Cl}$ for the incidence of severe difficulty

\section{Visual-vestibular system}

\section{Visual pursuits}

Less than half $(41.7 \%)$ of the individuals could execute visual pursuits without challenges, while $54.2 \%$ experienced moderate to severe challenges (Table VIII).
Table VIII: Visual pursuits

\begin{tabular}{|c|c|c|c|c|c|}
\hline \multirow[t]{2}{*}{ Aspect } & \multirow[t]{2}{*}{ Normal } & \multicolumn{3}{|c|}{ Severity of problem } & \multirow{2}{*}{$\begin{array}{l}95 \% \\
\mathrm{Cl}^{*}\end{array}$} \\
\hline & & Slight & Moderate & Severe & \\
\hline $\begin{array}{l}\text { Visual } \\
\text { pursuits } \\
(n=48)\end{array}$ & $\begin{array}{c}20 \\
(41.7 \%)\end{array}$ & $2(4.2 \%)$ & $14(29.2 \%)$ & $\begin{array}{c}12 \\
(25.0 \%)\end{array}$ & $\begin{array}{l}\text { [14.9\%; } \\
38.8 \%]\end{array}$ \\
\hline
\end{tabular}

$* 95 \% \mathrm{Cl}$ for the incidence of severe difficulty

\section{DISCUSSION}

The demographic results (Table $I$ ) indicate that the participants of this study were in their early and middle adulthood. The median age for this sample was 32 years and this is supported by the statistics of the specific institution where the individuals were admitted ${ }^{20}$. Sadock and Sadock ${ }^{8: 468}$ reports that males will present with the first episode of schizophrenia at a earlier age than females. This is supported by the results (Table I), that indicate that $65.3 \%$ of the sample were male.

The results (Table I) of this study implies that individuals present with psychotic symptoms at an early age. According to Sadock and Sadock ${ }^{8: 488-469}$ most male individuals with schizophrenia have their first episode before the age of 25 years. This correlates with the results in Table I and will also explain why $65.3 \%$ of the individuals of this sample were male. Approximately $90 \%$ of individuals that receive treatment for schizophrenia are between the ages of 15 and 55 years $^{8}$.

The average age at which bipolar disorder is diagnosed is 30 years ${ }^{(529)}$, but lately diagnosis is made at an earlier age (early twenties) and a possible explanation can be the use of cannabis and other drugs amongst the youth. According to Table I, $44.9 \%$ of the sample tested positive for cannabis abuse. According to Sadock and Sadock ${ }^{8}, 70 \%$ of individuals with bipolar disorder and $90 \%$ of individuals with schizophrenia abuse substances. Perlis ${ }^{21}$ supports this statement and said that $40 \%$ to $60 \%$ of individuals with bipolar disorder are lifelong abusers of substances.

The results (Table I) indicate that the majority $(79.6 \%)$ of the sample's HIV-status was unknown. This could have been due to fact the individuals were not tested or their HIV-status were possibly not declared to the ward staff. This could have influenced the results (frequency of sensory integration problems), but the authors could not find any information on HIV and sensory integration. Due to the fact that the individual with positive HIV-status can be more sensitive to the medication, they can present with more side-effects. This could also possibly have influenced the results and the incidence of sensory integration problems.

The SBC results of this sample of individuals with disorders characterised by symptoms of psychosis indicated that they experienced sensory integration difficulties. Thus, the question of this research has been answered. These results are supported by King ${ }^{5}$ who confirmed the presence of poor sensory processing within the proprioceptive system of individuals with schizophrenia. Kings' findings ${ }^{5}$ are further substantiated by Levine et al. ${ }^{6}$ and Bailey ${ }^{7}$, who found that individuals with schizophrenia experience poor balance and equilibrium, poor postural control, bilateral coordination difficulties, shuffling gait and illogical speech. The results of the vestibular and proprioceptive system functions indicated a high incidence of severe difficulty with the primary reflexes that are foundational in postural control, balance, equilibrium, bilateral coordination and body image, and optimal support of sensory-motor functions could thus have been comprimised ${ }^{18}$. Questions that arose were: (I) will sensory integration problems identified influence the occupational performance of the individual with psychosis; and (2) will sensory integration intervention have a positive influence on the occupational performance of the individual with psychosis?

Praxis disorders can be defined as the inability to plan, visualise (ideation) and/or execute novel motor activities ${ }^{22}$. The ability to plan, visualise and/or execute novel motor activities is supported by postural control, upper extremities functioning, body image, 
balance and equilibrium, and the level of integration of reflexes. The SBC findings in this study indicated that a high percentage of the individuals experienced moderate to severe difficulties with the aspects. The results also supported a high incidence of severe difficulties in bilateral coordination, midline crossing, Sharpened Romberg (eyes opened and closed), tonic labyrinthine reflex, body image and finger-thumb opposition. The processing abilities of the vestibular, tactile and proprioceptive sensory systems of the participants in this research are thus questionable.

Sensory integration problems can contribute to the fact that the individual with psychosis presents with functional problems that impact negatively on their occupational performance'. However, it remains possible that neurological changes, due to pathology, could have influenced the functioning of the sensory systems involved in sensory integration negatively and therefore contributed to the incidence of sensory integration problems. The integrity of the central nervous system in terms of the sensory integration of the individual with psychosis should therefore be viewed with reservation and the influence thereof should be considered by occupational therapists trained in sensory integration, when individuals with psychosis receive sensory integration intervention

There are limitations related to this study that need consideration. One of the limitations was the SBC as measuring instrument. No information could be obtained regarding the psychometrics of the test, but studies were found where the instrument was also used and that can be seen as support for the use of the test for research purposes. Due to logistics and time constraints, the SBC was only administered on the sample described in this study and not on the other sample that formed part of the bigger study. No control or comparison was therefore possible.

\section{CONCLUSION AND RECOMMENDATIONS}

This research project has not only highlighted the lack of literature and research on the topic, but supports the fact that the individuals with psychosis, who participated in this study, experienced sensory integration problems. Sensory integration as a frame of reference can address the functionality and the occupational performance of the individual with mental health problems' and can therefor possibly address the functional limitations of the individual with psychosis. This implies that sensory integration intervention can possibly be used in the treatment of the individuals with psychosis and that side-effects and neurological signs of the illness can possibly be addressed. The authors recommend that more research be done on the incidence and types of sensory integration problems that are experienced by individuals with mental illness.

This study is a foundation for future research in this field. It can be used by occupational therapists, trained in sensory integration, to establish a sensory integration treatment regime or to do research on the influence of sensory integration on the occupational performance of the individual with psychosis. Further research on the influence of HIV and cannabis abuse on sensory integration is also warranted.

\section{ACKNOWLEDGEMENTS}

The researchers thank all the individuals and the institution where the research was conducted for granting permission for the conducting of the research. A special word of thanks to the Crouch Psychiatric Trust for the financial contribution to the study. We also thank Dr. Daleen Struwig, Faculty of Health Sciences, for technical and editorial preparation of the manuscript. This research project was done as part of a Master's degree in Occupational Therapy at the University of the Free State.

\section{REFERENCES}

I. Alers VM. Sensory integrative therapy for adult psychiatry. In Crouch RB \& Alers V (eds). Occupational Therapy in Psychiatry and Mental Health. $3^{\text {rd }}$ ed. Cape Town: Maskew Miller Longman; 1997; 329-347.

2. Occupational Therapy Practice Framework: Domain and Process.
Third $^{\text {rd }}$ edition. American Journal of Occupational Therapy, 2014; 68(I): S6-S8.

3. Smith-Roley SS, Mailloux Z, Miller-Kuhaneck H, Glennon T. Understanding Ayres sensory integration. Occupational Therapy Practice, 2007; 12(17): I-6.

4. Bailey DM. The effects of vestibular stimulation on verbalization in chronic schizophrenics. American Journal of Occupational Therapy, 1978; 32(7): 445-450.

5. King LJ. A sensory-integrative approach to schizophrenia. American Journal of Occupational Therapy, 1974; 28(9): 529-536.

6. Levine I, O'Connor H, Stacey B. Sensory integration with chronic schizophrenics: a pilot study. Canadian Journal of Occupational Therapy, 1977; 44(I): I7-2I.

7. Annandale JCA. The short-term influence of sensory integration intervention on the mental health care user with disorders characterised by symptoms of psychosis. Unpublished Master's dissertation. Bloemfontein: University of the Free State, 2013.

8. Sadock BJ, Sadock VA. Synopsis of Psychiatry. $10^{\text {th }}$ ed. Philadelphia: Wolters Kluwer/Lippincott Williams \& Wilkins, 2007.

9. Uys L, Middleton L. Mental Health Nursing: a South African Perspective. $4^{\text {th }}$ ed. Cape Town: JUTA Academic, 2004.

10. American Psychiatric Association. Diagnostic and Statistical Manual of Mental Disorders V. $5^{\text {th }}$ ed. Washington, DC: American Psychiatric Association, 2013.

II. Leedy PD, Ormrod JE. Practical Research: Planning and Design. $9^{\text {th }}$ ed. New Jersey: Pearson Merill, 2010.

12. American Psychiatric Association. Diagnostic and Statistical Manual of Mental Disorders IV. 4th revised ed. Washington, DC: American Psychiatric Association, 2000.

13. Van Schroeder C, Block MP, Trottier EC, Stowell MS. Schroeder, Block and Campbell Adult Psychiatric Sensory Integration Evaluation Manual. $3^{\text {rd }}$ ed. Hawaii: Schroeder Publishing, 1993.

14. Bruce MAG, Borg B. Psychosocial Frames of Reference: Core for Occupation-based Practice. $3^{\text {rd }}$ ed. Thorofare, NJ, USA: Slack Incorporated, 2002.

15. Evans J, Salim AA. A cross-cultural test of the validity of occupational therapy assessments with patients with schizophrenia. American lournal of Occupational Therapy. 1992; 46(8): 686-693.

16. Koomar JA, Bundy AC. Creating direct intervention from theory. In Bundy AC, Lane SJ, Murray EA (eds.). Sensory Integration: Theory and Practice. $2^{\text {nd }}$ ed. Philadelphia: FA Davis Company, 2002; 26I300.

17. Goddard S. Reflexes, Learning and Behaviour: A Window into the Child's Mind. Eugene, OR, USA: Fern Ridge Press, 2005.

18. South African Institute of Sensory Integration Research Committee. Clinical Observations - Administration and Interpretation, Adapted From Ayres JA. Revised ed. South Africa: SAISI, 2005.I8.

19. Altman DG, Machin D, Bryant TN, Gardner MJ. Statistics With Confidence. 2nd ed. London: BMJ Books, 2002.

20. Free State Psychiatric Complex. Hospital Essential Data Set of the Free State Province. March 2012-July 2012. Bloemfontein: FSPC, 2013.

21. Perlis RH. Bipolar Disorder. 2008. (In Stern TA, Rosenbaum JF, Fava M, Bierderman J \& Rauch SL. Massachusetts General Hospital Comprehensive Clinical Psychiatry. United States of America: Mosby Elsevier, 2008.).

22. Bundy AC. Assessing sensory integration dysfunction. In Bundy AC, Lane SJ, Murray EA (eds.). Sensory Integration: Theory and Practice. $2^{\text {nd }}$ ed. Philadelphia: FA Davis Company, 2002; 169-187. 